\title{
Prospective Study of Serum Cysteine Levels and Oesophageal and Gastric Cancers in China
}

\author{
Gwen Murphy ${ }^{1}$, Jin-Hu Fan ${ }^{2}$, Steven D. Mark ${ }^{3}$, Sanford M. Dawsey ${ }^{1}$, Jacob Selhub ${ }^{4}$, \\ Jianbing Wang ${ }^{2}$, Philip. R. Taylor ${ }^{1}$, You-Lin Qiao ${ }^{2}$, and Christian C. Abnet ${ }^{1}$ \\ ${ }^{1}$ Division of Cancer Epidemiology and Genetics, National Cancer Institute, National Institutes of \\ Health, Bethesda, MD \\ ${ }^{2}$ Department of Epidemiology, Cancer Institute, Chinese Academy of Medical Sciences, Beijing, \\ People's Republic of China \\ ${ }^{3}$ Biostatistics \& Informatics, University of Colorado, Denver, CO \\ ${ }^{4}$ Jean Mayer U.S. Department of Agriculture Human Nutrition Research Center on Aging at Tufts \\ University, Boston, MA
}

\begin{abstract}
Background-Cancers of the upper gastrointestinal tract remain a significant cause of morbidity and mortality. Cysteine, known to be involved in a myriad of immuno-modulatory, anti-oxidant, and anti-carcinogenic pathways, has not been investigated in the aetiology of oesophageal or gastric cancers. To examine the relationship between serum cysteine concentration and risk of these cancers we conducted a nested case-cohort study within the General Population Nutrition Intervention Trial in Linxian, China.
\end{abstract}

Methods-498 oesophageal squamous cell carcinomas (OSCC) and 255 gastric cardia adenocarcinomas (GCA) were matched by age and sex to 947 individuals from the wider cohort. We calculated hazard ratios (HR) and 95\% confidence intervals (95\% CI) using the case-cohort estimator for the Cox proportional hazards models, stratified on age and sex, with adjustment for potential confounders.

Results-Higher concentrations of serum cysteine were significantly associated with a lower risk of both OSCC and GCA. For those in the highest quartile of serum cysteine, compared to those in the lowest, the multivariate HRs were 0.70 for $\operatorname{OSCC}(95 \% \mathrm{CI}: 0.51,0.98)$ and 0.59 for GCA (95\% CI: $0.38,0.91)$. These associations were dose dependent ( $P$ for trend $=0.006$ and 0.008 , respectively). These inverse associations were not significantly modified by other risk factors, with the exception of age, where a stronger association was noted among persons in the older age strata.

\footnotetext{
Correspondence to: Gwen Murphy, Ph.D., M.P.H., Nutritional Epidemiology Branch, DCEG, National Cancer Institute, 6120 Executive Blvd., EPS 3034, Rockville, MD 20892, Phone: 301-496-8894; Fax: 301-496-6829; murphygw@ @ail.nih.gov; In China: You-Lin Qiao, M.D., M.P.H., Ph.D., Department of Cancer Epidemiology, Cancer Institute, Chinese Academy of Medical Sciences, P.O. Box 2258, Beijing 100021, People's Republic of China; qiaoy@ cicams.ac.cn.

Disclosure of Potential Conflicts of Interest: None to declare.

The Corresponding Author has the right to grant on behalf of all authors and does grant on behalf of all authors, an exclusive licence (or non exclusive for government employees) on a worldwide basis to the BMJ Publishing Group Ltd and its Licensees to permit this article (if accepted) to be published in Gut editions and any other BMJPGL products to exploit all subsidiary rights, as set out in our licence (http://group.bmj.com/products/journals/instructions-for-authors/licence-forms).
} 
Conclusion-Higher serum concentrations of cysteine were associated with a significantly reduced risk of OSCC and GCA. Cysteine should be further investigated for its potential as a chemopreventive agent for upper gastrointestinal cancers.

\section{Keywords}

oesophageal squamous cell carcinoma; gastric cardia cancer; hazard ratio; cysteine

\section{Introduction}

Cysteine, a non-essential amino acid and metabolite of methionine, is an essential component of the one-carbon metabolism pathway that has been extensively investigated for its role in the synthesis and methylation of DNA and its possible role in carcinogenesis [1, 2]. Cysteine can be synthesized by the body under normal physiological conditions, if a sufficient quantity of methionine is available; most high-protein foods, such as pork, chicken, turkey, eggs, milk and yogurt, contain cysteine. Cysteine has many functions besides its role in one-carbon metabolism. A multi-faceted amino-acid, cysteine can modulate the immune response by inhibiting activation of nuclear factor- $\kappa \mathrm{B}(\mathrm{NF}-\kappa \mathrm{B})$ and the expression of several NF- $\kappa \mathrm{B}$ dependent genes [3]. It can also stimulate proliferation of lymphocytes and T-cell clones under experimental conditions [3]. Evidence from both human and animal studies suggests that cysteine also exerts direct anti-carcinogenic properties, since it can bind to and detoxify acetaldehyde, a known mutagen and carcinogen $[4,5]$. A recent study involving rats exposed to environmental cigarette smoke showed that orally administered $N$-acetylcysteine effectively modulated smoke-induced alterations of microRNA expression in rat lungs [6]; specifically, $N$-acetylcysteine modulated microRNAs involved in NF- $\mathrm{kB}$-mediated stress and P53 functions. Further, cysteine availability is a rate-limiting step in the formation of glutathione ( $\gamma$-glutamyl-cysteinyl-glycine), an antioxidant tri-peptide with critical roles in nutrient metabolism and wider homeostasis (gene expression, DNA and protein synthesis, cell proliferation and apoptosis, signal transduction, cytokine production and immune response and protein glutathionylation) [7, 8]. Glutathione may also modulate cell death in that high intracellular glutathione levels prevent cell death where low levels enhance it, so that glutathione depletion can activate apoptosis [9]. Immune activation may also be modulated by glutathione: it is essential for activation of T-lymphocytes, polymorphonuclear leukocytes and cytokine production [10].

Cancers of the upper gastrointestinal tract remain a significant cause of morbidity and mortality. In 2002 there were an estimated 934,000 new cases of stomach cancer and 462,000 cases of oesophageal cancer, globally, and with a poor prognosis for both cancers, they ranked as the second and sixth leading causes of cancer-related mortality worldwide [11]. In Linxian, China, where this study was based, cancer of the upper gastrointestinal tract is endemic; mortality rates for oesophageal cancer in Linxian exceed the Chinese average by 10 -fold and the American average (for white men) by 100-fold [12].

Cysteine is involved in a range of pathways relevant to carcinogenesis, yet there is a striking dearth of epidemiological studies investigating its role in the aetiology of cancer. To our knowledge, plasma cysteine concentrations have previously been measured only in the context of breast and cervical cancers $[13,14,15]$; given the potential relevance of cysteine to inflammatory and other pathways involved in both oesophageal and gastric carcinogenesis, we investigated the association between serum cysteine concentration and risk of oesophageal squamous cell carcinoma and gastric cardia adenocarcinoma in a casecohort study nested in the General Population Nutrition Intervention Trial in Linxian, China. 


\section{Methods}

Subjects in this study were selected from the participants of the Linxian General Population Nutrition Intervention Trial. Details of the design, intervention agents, conduct, and primary end-point analyses of this trial have been published elsewhere [16, 17]. Briefly, the 29,584 healthy adult trial participants were aged between 40-69 years and came from four Linxian communes. One year prior to the intervention each participant was interviewed, given a brief physical examination and had 10mL of blood drawn. The intervention began in March 1986 and continued through May 1991. Participants were randomly assigned to receive either a vitamin-mineral combination or a placebo, in accordance with the partial factorial design of the trial. Four different vitamin-mineral combinations were tested: Factor A $(10,000 \mathrm{IU}$ of vitamin A and $45 \mathrm{mg}$ of zinc oxide), Factor B (52mg of riboflavin and 40mg of niacin),

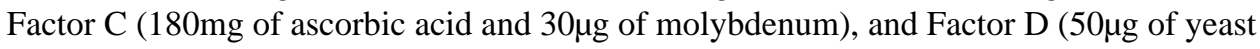
selenium, $15 \mathrm{mg}$ of $\beta$-carotene, and 30mg of a-tocopherol). Mortality and possible symptoms of cancer among trial participants were ascertained by local village doctors through monthly follow-up, and $<1 \%$ of the participants were lost to follow-up during the study period. Diagnoses of cancer were made at local commune and county hospitals and supplemented by a study team which provided clinical and diagnostic services, including endoscopy, for patients with symptoms suggestive of oesophageal or gastric cancer. A panel of U.S. and Chinese experts reviewed the diagnostic material for $85 \%$ of the cancer cases in this study. Cancers in the most proximal $3 \mathrm{~cm}$ of the stomach were defined as cardia cancers and those originating elsewhere in the stomach were designated non-cardia cancers. Ninetyfive percent of the anatomic localizations were made with the use of endoscopy, surgery, and/or X-rays. Senior Chinese diagnosticians conducted reviews for cancer cases without diagnostic materials and for deaths due to causes other than cancer. Written informed consent was obtained from each participant prior to enrolment, and human subject protection procedures approved by the institutional review boards of the U.S. National Institutes of Health and the Chinese Academy of Medical Sciences were followed throughout the trial.

\section{Selection of Study Participants for Serum Cysteine Measurement}

We used a stratified case-cohort design [18, 19, 20], to select individuals for serum measurements from the cohort of all participants in the General Population Trial. During the 5.25 years of the trial, 640 (oesophageal squamous cell carcinomas) OSCC and 435 gastric cardia adenocarcinomas (GCA) were identified [17]. Following a series of simulations and power calculations, 498 OSCC and $255 \mathrm{GCA}$ were randomly selected from the identified cases for inclusion in this analysis (see Table 1). Serum cysteine was also measured in a stratified random sample of all trial participants $(n=947$, also selected following power calculations), without regard to outcome, as the comparison group (referred to as the subcohort). Six strata were defined by sex and the following age categories (at the start of intervention): $<50$ years old; $50-60$ years old; and $>60$ years old. Cohort subjects were drawn from each stratum to achieve a greater than 1:1 ratio for control subjects to case subjects for both OSCC and GCA combined. The lowest within-stratum ratios of control subjects to case subjects for incident OSCC or GCA were 1.4 and 2.7, respectively. Overall, we measured serum cysteine concentrations in 947 subcohort subjects and 753 case subjects.

\section{Laboratory Analysis}

At the time of baseline interview (March-May 1985: one year before the initiation of the intervention), a $10 \mathrm{ml}$ venous blood sample was collected from all consenting participants. Samples were stored 3-6 hours on ice during transportation to the central field station where they were separated, aliquotted and stored at $-45^{\circ} \mathrm{C}$ for 3-4 days before being shipped to Beijing for long-term storage at $-85^{\circ} \mathrm{C}$. In 1996 , aliquots of these baseline sera were transferred to the National Cancer Institute repository on dry ice. Samples selected for 
inclusion in the cysteine analysis were thawed, and smaller aliquots were made, immediately refrozen and shipped on dry ice to the analytic laboratories (Jean Mayer U.S. Department of Agriculture Human Nutrition Research Center on Aging at Tufts University, Boston, MA).

Serum cysteine concentration was determined using a modified high performance liquid chromatography (HPLC) method [21]. Each batch contained adjacent blinded case and matched control samples, as well as six blinded quality control samples derived from a pool of serum from Linxian residents. The overall coefficient of variation in the $153 \mathrm{QC}$ samples was $13 \%$. Serum creatinine was also measured, and its overall coefficient of variation in the QC samples was $12 \%$.

\section{Statistical Analysis}

Mean and quantile values for serum cysteine were calculated using the sampling weights for the whole General Population Trial cohort, so that estimates are derived from the entire cohort, including those who may have later developed cancer. We used multivariable linear regression to examine the relationships between serum cysteine concentration and its possible predictors. In this linear regression model age was centred at 55 years (the middle of the sub-cohort age range) and body mass index (BMI, [weight in $\mathrm{kg}] /[\text { height in } \mathrm{m}]^{2}$ ) was centred at the sub-cohort median, $22 \mathrm{Kg} / \mathrm{m}^{2}$.

Follow-up time was measured from the start of the intervention, in March 1986, to any cancer diagnosis, loss to follow-up, or death. Hazard ratios (HRs) and 95\% confidence intervals (CIs) were calculated using the case-cohort estimator for the Cox proportional hazards models $[18,19,20,22]$. All estimates come from models stratified on the six sexage sampling strata. Adjustment for variation within age strata was made using stratumspecific age terms for continuous age. The proportionality assumption was examined using models that allowed time-dependent HRs and no evidence was found that HRs varied with time.

The relationship between cysteine and risk of OSCC or GCA was examined using a number of alternative metrics. Continuous estimates of cysteine were scaled to $19 \mathrm{nmol} / \mathrm{mL}(1 / 2$ the interquartile range: (75th percentile-25th percentile) $\div 2$ ). HRs were also estimated according to quartiles and ordinal values were assigned to the quartiles for trend tests.

Multivariate models were stratified on the 6 sex and age group categories used in the subcohort selection. Additional adjustments included separate continuous age variables for each stratum and variables for ever smoking, any alcohol intake in the previous 12 months, BMI (measured height and weight), serum creatinine $(\mathrm{mg} / \mathrm{dL}$ ) and serum creatinine squared (because of a non-linear association between creatinine and cysteine). Stratified models were also examined for sex, age, cigarette smoking and alcohol drinking. These stratified models included an interaction term (cross-product) and were fully adjusted for all other terms. As cigarette and alcohol consumption were almost completely restricted to men in this cohort, these stratified models are not presented for women.

To investigate the possibility the pre-clinical cancers may affect serum cysteine concentrations we examined whether the HR associated with cancer that developed in the first 2 years of the study differed from the HR associated with cancer that developed after 2 years. These differences were not significant for either OSCC $(P=0.70)$ or GCA $(P=0.89)$. The randomized nature of the original intervention meant that confounding by intervention status was unlikely; possible interaction between serum cysteine concentration and the intervention was examined and this was not significant. 


\section{Results}

Baseline characteristics of the cases and sub-cohort are shown in Table 1. Incident cancer cases included 498 OSCC and 255 GCA. There were almost twice as many GCA cases in men than in women, but the number of OSCC cases was about equal in men and women. The associations between smoking, alcohol and BMI and both gastric and oesophageal cancers have been previously reported for this population [23].

The median (and $25^{\text {th }}$ and $75^{\text {th }}$ percentile) serum cysteine concentrations (in $\mathrm{nmol} / \mathrm{mL}$ ) in the cases and cohort participants are shown in Table 2. The median serum cysteine concentration for the cohort was $196 \mathrm{nmol} / \mathrm{mL}$ (IQR: $178-216 \mathrm{nmol} / \mathrm{mL}$ ), with no significant difference between males (median: $196 \mathrm{nmol} / \mathrm{mL}$; IQR: $179-215 \mathrm{nmol} / \mathrm{mL}$ ) and females (median: $196 \mathrm{nmol} / \mathrm{mL}$; IQR: 176-217 nmol/mL). With increasing age, the median serum cysteine concentration increased, from $188 \mathrm{nmol} / \mathrm{mL}$ (IQR: $168-204 \mathrm{nmol} / \mathrm{mL}$ ) in the $<50$ year old category to $203 \mathrm{nmol} / \mathrm{mL}$ (IQR: $186-225 \mathrm{nmol} / \mathrm{mL}$ ) and $212 \mathrm{nmol} / \mathrm{mL}$ (IQR: $193-231 \mathrm{nmol} / \mathrm{mL}$ ) in the $50-60$ and $>60$ year old categories. The median cysteine concentrations for OSCC and GCA cases were $191 \mathrm{nmol} / \mathrm{mL}$ (IQR: $172-211 \mathrm{nmol} / \mathrm{mL}$ ) and $198 \mathrm{nmol} / \mathrm{mL}$ (IQR: $179-215 \mathrm{nmol} / \mathrm{mL}$ ), respectively.

The paucity of data regarding the predicators of serum cysteine concentrations generally, (in any population) led us to investigate such factors in this population (Table 3). Age and BMI were significantly positively related and serum creatinine level was significantly inversely related to serum cysteine concentration.

Serum cysteine was significantly inversely associated with risk of both OSCC (HR: 0.86; 95\% CI: 0.79, 0.93) and GCA (HR: 0.81; 95\% CI: 0.73, 0.90) after adjusting for age, sex, cigarette smoking, alcohol drinking, BMI, and serum creatinine (Table 4). In quartile analysis, risk of both OSCC and GCA decreased significantly from the lowest to the highest quartile of serum cysteine ( $P_{\text {trend }}=0.006$ and $P_{\text {trend }}=0.008$, respectively). Those in the top two quartiles of serum cysteine had a significantly lower risk of OSCC, relative to those in the lowest quartile (HR: 0.61, 95\% CI: 0.44, 0.86 and HR: 0.70, 95\% CI: 0.51, 0.98 for quartiles 3 and 4, respectively). Those in the highest quartile of serum cysteine also had a significantly lower risk of GCA, relative to those in the lowest quartile (HR: 0.59, 95\% CI: $0.38,0.91)$.

Adjusted hazard ratios for risk of OSCC and GCA stratified by sex, age, cigarette smoking and alcohol drinking are presented in Table 5. Significant interactions were noted between age and serum cysteine concentration for both OSCC $(\mathrm{P}=0.00014)$ and GCA $(\mathrm{P}<0.0001)$; the inverse association between serum cysteine concentration and both tumours was stronger among older people.

\section{Discussion}

In this large prospective cohort, we found that higher serum cysteine concentrations were associated with significantly reduced risk of both OSCC and GCA. Those in the highest quartile of serum cysteine had a $30 \%$ lower risk of OSCC and a $40 \%$ lower risk of developing GCA relative to those in the lowest quartile. These inverse associations were stronger for those in the older age groups for both cancer sites. Of note, the serum cysteine concentrations reported here (median: $196 \mathrm{nmol} / \mathrm{mL}$; IQR: $178-196 \mathrm{nmol} / \mathrm{mL}$ ) were significantly lower than those reported for healthy/control subjects in the UK (median: 240nmol/L; IQR: 216-262 nmol/L) [24] and Norway (median: $318 \mathrm{nmol} / \mathrm{L}$; IQR: 289-337 $\mathrm{nmol} / \mathrm{L})[25]$. 
This is the first study to evaluate the relationship between serum cysteine concentration and risk of oesophageal or gastric cancer. Indeed, we could identify just 3 studies that have looked at (plasma) cysteine in the context of malignancies at other sites. Most recently, one study examined the association between cysteine, homocysteine, and cancer risk in 812 invasive breast cancer cases and matched controls [14]. This group reported a positive association between cysteine and breast cancer risk; those in the highest quintile of plasma cysteine had a relative risk of 1.65 (95\% CI: 1.04, 2.61) compared to those in the lowest quintile, and the association was dose-dependent $\left(\mathrm{P}_{\text {trend }}=0.04\right)$. In contrast, an investigation of 712 incident in situ and invasive breast cancer cases found that women in the highest quintile of plasma cysteine had a significantly lower risk of breast cancer relative to those in the lowest quintile (RR: 0.44 ; 95\% CI: $0.26,0.74$ ), and this inverse association was dosedependent $\left(P_{\text {trend }}=0.002\right)$ [15]. Lastly, a study of 147 women with squamous intraepithelial lesions of the cervix, 185 women with atypical squamous cells of undetermined significance (ASCUS), and 191 women with cytologically normal Pap smears reported that women in the highest quartile of plasma cysteine had a significantly lower risk of ASCUS than those in the lowest quartile (OR: 0.3 ; 95\% CI: 0.2, 0.7) [13]. Given the large number of biologic pathways which cysteine is known to modulate, either directly or indirectly, it may not be surprising that it has been both positively and inversely associated with cancer risk in previous studies: it's role in carcinogenesis is likely determined by both tumour type and physiologic context.

While our results suggest some potential for cysteine (or the related $N$-acteylcysteine) as a chemopreventive agent, evidence from the few reported animal and human studies is mixed. In a rat model where oesophageal papillomas and squamous cell carcinomas and liver tumours were induced, oral administration of $\mathrm{N}$-acetylcysteine significantly reduced the multiplicity of oesophageal tumours but had no effect on the incidence or multiplicity of liver tumours [26]. A second study, using a rat model of oesophageal adenocarcinoma where tumours were induced via oesophagogastroduodenal anastomosis, reported that $N$ acetylcysteine alone did not significantly decrease the incidence of oesophageal adenocarcinomas; however $\mathrm{N}$-acetylcysteine in combination with a-tocopherol produced a significant reduction in tumour incidence [27]. Further evidence from animal studies suggests that $N$-acetylcysteine dose may be critical in determining its effect. In a rat mammary cancer model, a low dose of $\mathrm{N}$-acetylcysteine modestly decreased, and a high dose significantly increased, tumour occurrence [28]. The single study that we have identified which related to gastric cancer reported that $N$-acetylcysteine inhibited human gastric cancer SJ-89 cell growth by inducing apoptosis and DNA synthesis arrest [29]. A randomized trial of 2592 former or current smokers with head and neck or lung cancers found no effect on survival or the incidence of second primary tumours following 2 years of $N$-acetylcysteine supplementation [30]. On the other hand, a small study of 7 volunteers found that carcinogenic acetaldehyde produced by smoking cigarettes could be completely inactivated by sucking a tablet containing $5 \mathrm{mg}$ of ${ }_{\mathrm{L}}$-cysteine [4], suggesting some potential for cysteine as a chemopreventive agent in certain settings.

Without accurate assessment of dietary intake, it is impossible to tell whether serum cysteine may correlate with general protein intake in the current study population. In another analysis from the same cohort, individuals eating meat more than 12 times a year had a significantly reduced risk of OSCC (relative to those who ate meat less than 4 times a year). Higher egg consumption ( $>36$ times/year, relative to 2 or fewer times/year) was associated with a significantly reduced risk of both OSCC and GCA [31]. However, it is likely that higher intake of protein (namely meat and eggs) is a proxy for both higher socioeconomic status and higher general nutritional status. 
Our study has a number of strengths, including the prospective study design, the large number of cancer cases, the availability of data on potential confounders, a state-of-the-art measurement method for serum cysteine concentrations and the virtually complete followup of all study participants.

Our study also has several limitations. As with any study of this kind, unidentified, unmeasured confounders could explain the association we report (for Table 3 the total model $\mathrm{r}^{2}=0.18$ ). The large size of the study, the precision of the lab analyses, the close follow-up of trial participants, and the rigorous documentation of cancer diagnoses suggest that neither exposure nor disease misclassification are likely to have significantly influenced our estimates. There is always a concern that pre-clinical disease could lead to alterations in serum measurements, thus creating a misleading association, but we found no difference in the exposure-disease associations between those with cancers diagnosed within the first 2 years of the study and those diagnosed after 2 years. Cysteine participates in a myriad of biological pathways and the specific pathways involved in the risk reduction we observed are not clear. Lastly, the generalisability of our study may be limited, due to the specificities of the population under study (see Table 1). In particular, low protein intake in this population [32] may be associated with the relatively low range of serum cysteine concentrations which we found.

In this large prospective population study, we found that individuals with higher baseline serum concentrations of cysteine were associated with a significantly reduced risk of both OSCC and GCA. These associations appear biologically plausible. Cysteine should be investigated for it's potential as a chemopreventive agent for upper gastrointestinal cancers.

\section{Acknowledgments}

Funding: This work was supported by the Intramural Research Program, Division of Cancer Epidemiology and Genetics, the National Cancer Institute, at the National Institutes of Health, Department of Health and Human Services.

\section{Abbreviations \\ OSCC oesophageal squamous cell carcinoma \\ GCA gastric cardia cancer}

\section{References}

1. Choi S-W, Mason JB. Folate and Carcinogenesis: An Integrated Scheme1-3. J Nutr. 2000; 130:129-132. [PubMed: 10720158]

2. Bailey, LB.; Moyers, S.; Gregory, JF, III. Bowman, BS.; Russell, RM. Present Knowledge in Nutrition. Washington, DC: Internation Life Sciences Institute; 2001. Folate.

3. Droge W, Eck HP, Gmunder H, et al. Modulation of lymphocyte functions and immune responses by cysteine and cysteine derivatives. Am J Med. 1991; 91:140S-144S. [PubMed: 1928206]

4. Salaspuro VJ, Hietala JM, Marvola ML, et al. Eliminating carcinogenic acetaldehyde by cysteine from saliva during smoking. Cancer Epidemiol Biomarkers Prev. 2006; 15:146-149. [PubMed: 16434601]

5. Izzotti A, Balansky RM, Dagostini F, et al. Modulation of biomarkers by chemopreventive agents in smoke-exposed rats. Cancer Res. 2001; 61:2472-2479. [PubMed: 11289117]

6. Izzotti A, Calin GA, Steele VE, et al. Chemoprevention of cigarette smoke-induced alterations of MicroRNA expression in rat lungs. Cancer Prev Res (Phila Pa). 3:62-72.

7. Wu G, Fang YZ, Yang S, et al. Glutathione metabolism and its implications for health. J Nutr. 2004; 134:489-492. [PubMed: 14988435] 
8. Hammond CL, Lee TK, Ballatori N. Novel roles for glutathione in gene expression, cell death, and membrane transport of organic solutes. J Hepatol. 2001; 34:946-954. [PubMed: 11451183]

9. Celli A, Que FG, Gores GJ, et al. Glutathione depletion is associated with decreased Bcl-2 expression and increased apoptosis in cholangiocytes. Am J Physiol. 1998; 275:G749-G757. [PubMed: 9756506]

10. Townsend DM, Tew KD, Tapiero H. The importance of glutathione in human disease. Biomed Pharmacother. 2003; 57:145-155. [PubMed: 12818476]

11. Parkin DM, Bray F, Ferlay J, et al. Global Cancer Statistics, 2002. CA Cancer J Clin. 2005; 55:74108. [PubMed: 15761078]

12. Blot WJ, Li JY. Some considerations in the design of a nutrition intervention trial in Linxian, People's Republic of China. Natl Cancer Inst Monogr. 1985; 69:29-34. [PubMed: 3914622]

13. Goodman MT, McDuffie K, Hernandez B, et al. Case-control study of plasma folate, homocysteine, vitamin B(12), and cysteine as markers of cervical dysplasia. Cancer. 2000; 89:376-382. [PubMed: 10918169]

14. Lin J, Lee I-M, Song Y, et al. Plasma Homocysteine and Cysteine and Risk of Breast Cancer in Women. Cancer Res. 2010; 70:2397-2405. [PubMed: 20197471]

15. Zhang SM, Willett WC, Selhub J, et al. A prospective study of plasma total cysteine and risk of breast cancer. Cancer Epidemiol Biomarkers Prev. 2003; 12:1188-1193. [PubMed: 14652279]

16. Li B, Taylor PR, Li JY, et al. Linxian nutrition intervention trials. Design, methods, participant characteristics, and compliance. Ann Epidemiol. 1993; 3:577-585. [PubMed: 7921303]

17. Blot WJ, Li JY, Taylor PR, et al. Nutrition intervention trials in Linxian, China: supplementation with specific vitamin/mineral combinations, cancer incidence, and disease-specific mortality in the general population. Journal of the National Cancer Institute. 1993; 85:1483-1492. [PubMed: 8360931]

18. Mark SD, Katki H. Influence function based variance estimation and missing data issues in casecohort studies. Lifetime Data Anal. 2001; 7:331-344. [PubMed: 11763542]

19. Prentice RL. A case cohort design for epidemiologic cohort studies and disease prevention trials. Biometrika. 1986; 73:1-11.

20. Self SG, Prentice RL. Asymptomatic distribution theory and efficiency results for case-cohort studies. Ann Stat. 1988; 16:64-81.

21. Araki A, Sako Y. Determination of free and total homocysteine in human plasma by highperformance liquid chromatography with fluorescence detection. J Chromatogr. 1987; 422:43-52. [PubMed: 3437026]

22. Epicure. Seattle, WA: Hirosoft International Corporation; 1998.

23. Guo W, Blot WJ, Li JY, et al. A nested case-control study of oesophageal and stomach cancers in the Linxian nutrition intervention trial. International journal of epidemiology. 1994; 23:444-450. [PubMed: 7960367]

24. Huengsberg M, Waring R, Moffitt D, et al. Serum cysteine levels in HIV infection. AIDS. 1998; 12:1245. [PubMed: 9677175]

25. Muller F, Svardal A, Aukrust P, et al. Elevated plasma concentration of reduced homocysteine in patients with human immunodeficiency virus infection. Am J Clin Nutr. 1996; 63:242-248. [PubMed: 8561066]

26. Balansky RM, Ganchev G, D'Agostini F, et al. Effects of N-acetylcysteine in an esophageal carcinogenesis model in rats treated with diethylnitrosamine and diethyldithiocarbamate. International journal of cancer. 2002; 98:493-497.

27. Hao J, Zhang B, Liu B, et al. Effect of alpha-tocopherol, N-acetylcysteine and omeprazole on esophageal adenocarcinoma formation in a rat surgical model. International journal of cancer. $2009 ; 124: 1270-1275$.

28. Lubet RA, Steele VE, Eto I, et al. Chemopreventive efficacy of anethole trithione, N-acetyl-Lcysteine, miconazole and phenethylisothiocyanate in the DMBA-induced rat mammary cancer model. International journal of cancer. 1997; 72:95-101.

29. Li J, Tu HJ, Dai G, et al. N-acetyl cysteine inhibits human signet ring cell gastric cancer cell line (SJ-89) cell growth by inducing apoptosis and DNA synthesis arrest. Eur J Gastroenterol Hepatol. 2007; 19:769-774. [PubMed: 17700262] 
30. van Zandwijk N, Dalesio O, Pastorino U, et al. EUROSCAN, a randomized trial of vitamin A and $\mathrm{N}$-acetylcysteine in patients with head and neck cancer or lung cancer. For the EUropean Organization for Research and Treatment of Cancer Head and Neck and Lung Cancer Cooperative Groups. Journal of the National Cancer Institute. 2000; 92:977-986. [PubMed: 10861309]

31. Tran GD, Sun XD, Abnet CC, et al. Prospective study of risk factors for esophageal and gastric cancers in the Linxian general population trial cohort in China. International journal of cancer. 2005; 113:456-463.

32. Zou XN, Taylor PR, Mark SD, et al. Seasonal variation of food consumption and selected nutrient intake in Linxian, a high risk area for esophageal cancer in China. Int J Vitam Nutr Res. 2002; 72:375-382. [PubMed: 12596503] 


\section{Summary Box}

\section{What is already known about this subject?}

- Cancers of the stomach and oesophagus remain a significant cause of morbidity and mortality.

- Cysteine is a non-essential amino acid involved in immuno-modulatory, antioxidant, and anti-carcinogenic pathways.

- Though previously proposed as a chemopreventive agent, epidemiological studies of cysteine have produced equivocal results.

\section{What are the new findings?}

- In this large prospective cohort, higher serum cysteine concentrations are associated with a $30 \%$ lower risk of oesophageal squamous cell carcinoma and a $40 \%$ lower risk of gastric cardia adenocarcinoma.

- The inverse associations between serum cysteine and both oesophageal and gastric cancers are dose dependent.

\section{How might it impact clinical practice in the foreseeable future?}

- Cysteine warrants further investigation regarding its potential as a chemopreventive agent for upper gastrointestinal cancers. 


\section{Table 1}

Study characteristics of cases and the sub-cohort from the Linxian General Population Nutrition Intervention Trial cohort, overall and by sex.

\begin{tabular}{|l|l|l|l|}
\hline Variable & Sub-cohort & $\begin{array}{l}\text { Oesophageal } \\
\text { Squamous Cell } \\
\text { Carcinoma }\end{array}$ & $\begin{array}{l}\text { Gastric Cardia } \\
\text { Adenocarcinoma }\end{array}$ \\
\hline Number, Total N (\%) & 947 & 498 & 255 \\
\hline Men & $515(54 \%)$ & $241(48 \%)$ & $167(65 \%)$ \\
\hline Women & $432(46 \%)$ & $257(53 \%)$ & $88(35 \%)$ \\
\hline Age at baseline, Mean (SD) & $57(7.7)$ & $57(7.8)$ & $58(6.4)$ \\
\hline Men & $59(6.8)$ & $58(7.0)$ & $58(6.1)$ \\
\hline Women & $56(8.4)$ & $55(8.3)$ & $56(6.7)$ \\
\hline Cigarette Smoking, N (\%) yes ${ }^{\ddagger}$ & $364(38 \%)$ & $190(38 \%)$ & $118(46 \%)$ \\
\hline Men & $362(70 \%)$ & $190(79 \%)$ & $118(71 \%)$ \\
\hline Women & $2(<1 \%)$ & $0(0 \%)$ & $0(0 \%)$ \\
\hline Alcohol Drinking, N (\%) yes ${ }^{\S}$ & $200(21 \%)$ & $112(23 \%)$ & $58(23 \%)$ \\
\hline Men & $172(33 \%)$ & $95(39 \%)$ & $51(31 \%)$ \\
\hline Women & $28(6 \%)$ & $17(7 \%)$ & $7(8 \%)$ \\
\hline BMI (Kg/m ${ }^{2}$, Mean (SD) & $21.8(2.6)$ & $21.4(2.4)$ & $21.6(2.5)$ \\
\hline Men & $21.5(2.1)$ & $21.6(2.1)$ & $21.3(2.0)$ \\
\hline Women & $22.1(3.1)$ & $21.3(2.6)$ & $22.1(3.2)$ \\
\hline Serum Creatinine (mg/dL), Mean (SD) & $0.84(0.18)$ & $0.83(0.20)$ & $0.86(0.22)$ \\
\hline Men & $0.91(0.15)$ & $0.92(0.16)$ & $0.93(0.16)$ \\
\hline Women & $0.75(0.17)$ & $0.75(0.19)$ & $0.72(0.24)$ \\
\hline & & & \\
\hline
\end{tabular}

Some subjects who later developed one of these cancers are included in the randomly selected sub-cohort.

${ }^{*}$ Daily cigarette consumption among men was generally low and few subjects had quit smoking, so smoking is presented as never smoking versus ever smoking.

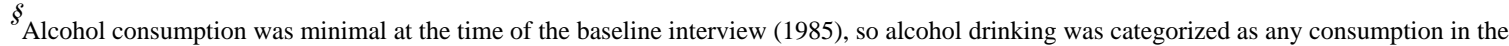
previous twelve months versus none 
Table 2

Serum cysteine concentration $(\mathrm{nmol} / \mathrm{mL})$ quantiles in the sub-cohort from the Linxian General Population Nutrition Intervention Trial cohort, overall and by sex, age, smoking, and drinking status.

\begin{tabular}{|c|c|c|c|}
\hline & \multicolumn{3}{|c|}{ Quantile } \\
\hline & $25^{\text {th }}$ & $50^{\text {th }}$ & $7^{\text {th }}$ \\
\hline \multicolumn{4}{|c|}{ General Population Trial Cohort ${ }^{*}$} \\
\hline Overall & 178 & 196 & 216 \\
\hline \multicolumn{4}{|l|}{ Sex } \\
\hline Men & 179 & 196 & 215 \\
\hline Women & 176 & 196 & 217 \\
\hline \multicolumn{4}{|l|}{ Age (in years) } \\
\hline$<50$ & 168 & 188 & 204 \\
\hline $50-60$ & 186 & 203 & 225 \\
\hline$>60$ & 193 & 212 & 231 \\
\hline \multicolumn{4}{|c|}{ Cigarette Smoking } \\
\hline Never smokers & 181 & 194 & 219 \\
\hline Ever smokers $t^{t}$ & 179 & 196 & 212 \\
\hline \multicolumn{4}{|c|}{ Alcohol Drinking $\S$} \\
\hline Non-Drinkers & 174 & 195 & 216 \\
\hline Drinkers $\mathcal{\xi}$ & 183 & 200 & 213 \\
\hline
\end{tabular}

* All concentrations are weighted by the age and sex sampling to reflect the distributions in the full cohort

Daily cigarette consumption among men was generally low and few subjects had quit smoking, so smoking is presented as never smoking versus ever smoking.

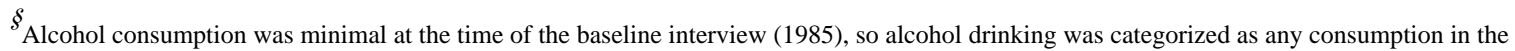
previous twelve months versus none 


\section{Table 3}

Predictors of serum cysteine concentration in the sub-cohort from the Linxian General Population Nutrition Intervention Trial cohort, from multivariable linear regression models.

\begin{tabular}{|l|l|l|l|}
\hline Variable & $\beta$ coefficient & Standard error & $\mathbf{P}$ \\
\hline Intercept & 242.41 & 12.063 & $<.0001$ \\
\hline Sex, male & -0.020 & 2.72 & 0.99 \\
\hline Age $^{*}, 1$ year & 1.38 & 0.1001 & $<.0001$ \\
\hline Cigarette Smoking, ever & -4.51 & 2.76 & 0.10 \\
\hline Alcohol Drinking, any & 3.54 & 2.30 & 0.13 \\
\hline BMI $^{*}, 1 \mathrm{~kg} / \mathrm{m}^{2}$ & 1.79 & 0.35 & $<.0001$ \\
\hline Creatinine, 0.12 units & -13.03 & 3.78 & 0.0006 \\
\hline Creatinine squared & 1.019 & 0.29 & 0.0005 \\
\hline
\end{tabular}

Age was centred at 55 years old in the model, the middle of the sub-cohort age distribution

Body mass index (BMI) was centred at 22 units, the sub-cohort median 


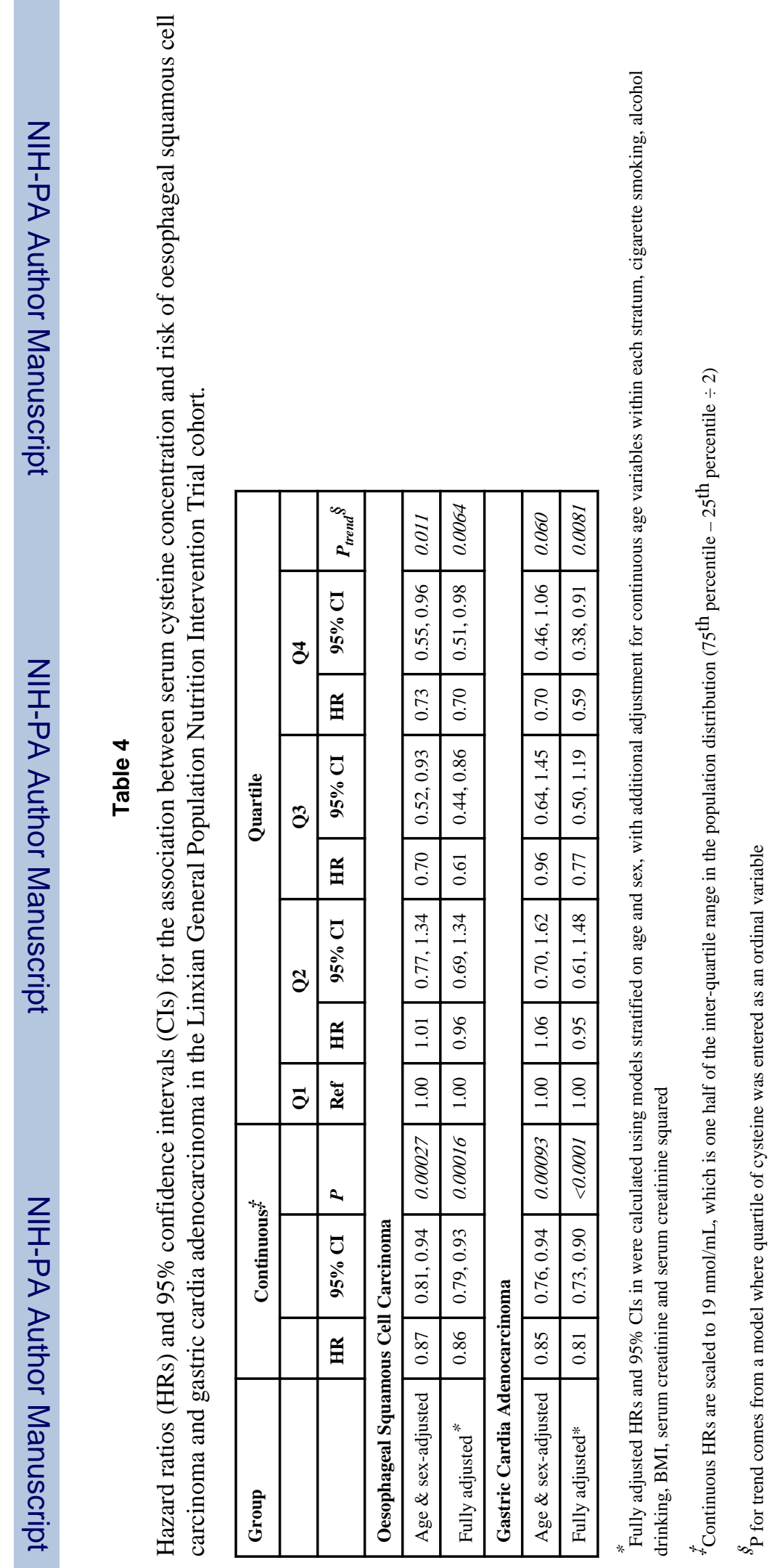




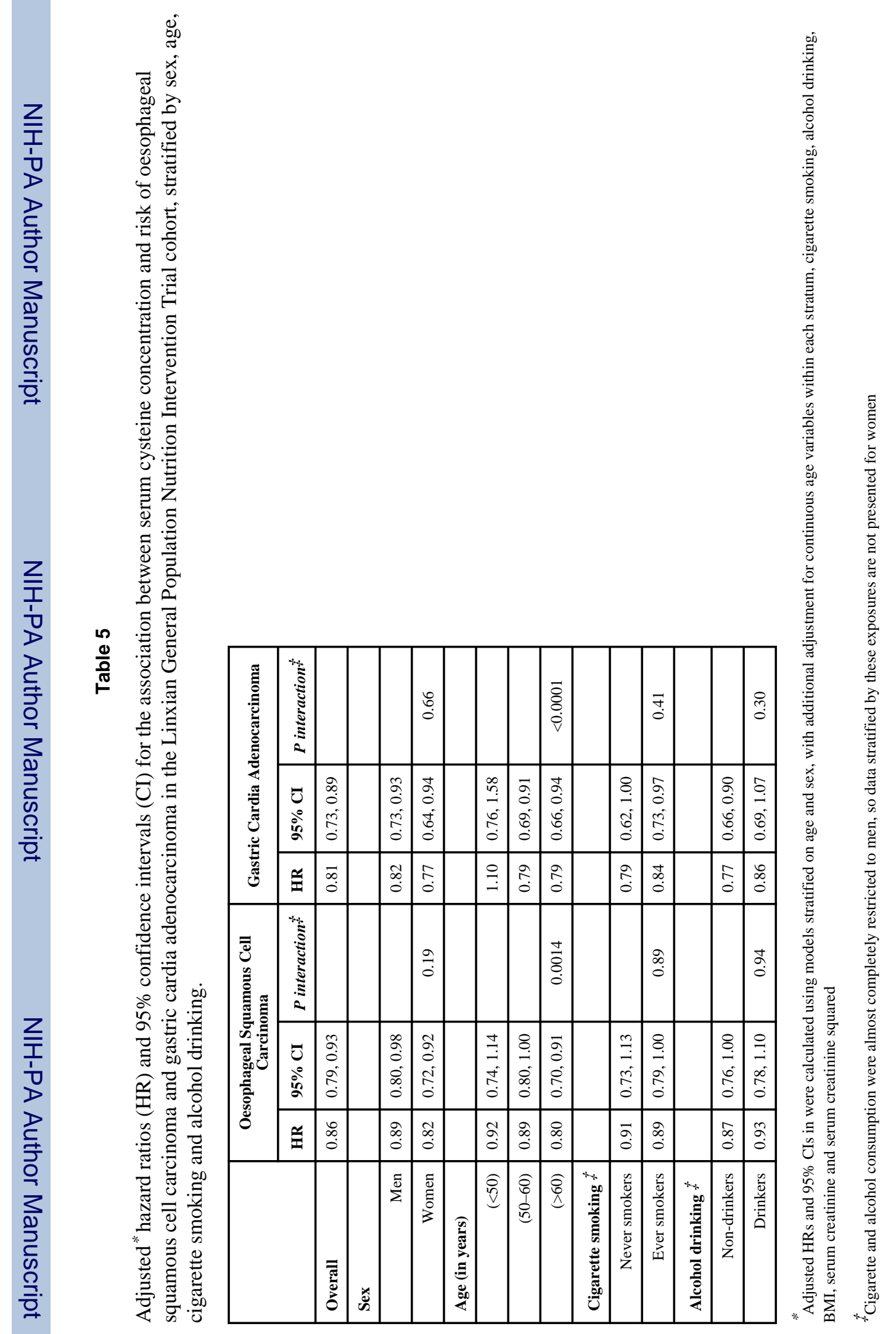

